\title{
Evidence for epistasis between SLC6A4 and ITGB3 in autism etiology and in the determination of platelet serotonin levels
}

\author{
Ana M. Coutinho $\cdot$ Inês Sousa $\cdot$ Madalena Martins $\cdot$ Catarina Correia $\cdot$ \\ Teresa Morgadinho $\cdot$ Celeste Bento $\cdot$ Carla Marques $\cdot$ Assunção Ataíde $\cdot$ \\ Teresa S. Miguel · Jason H. Moore · Guiomar Oliveira · Astrid M. Vicente
}

Received: 27 August 2006/ Accepted: 15 November 2006/Published online: 3 January 2007

(C) Springer-Verlag 2006

\begin{abstract}
Autism is a neurodevelopmental disorder of unclear etiology. The consistent finding of platelet hyperserotonemia in a proportion of patients and its heritability within affected families suggest that genes involved in the serotonin system play a role in this disorder. The role in autism etiology of seven can-
\end{abstract}

Electronic supplementary material The online version of this article (doi:10.1007/s00439-006-0301-3) contains supplementary material, which is available to authorized users.

\footnotetext{
A. M. Coutinho $\cdot$ I. Sousa $\cdot$ M. Martins .

C. Correia · A. M. Vicente $(\bowtie)$

Instituto Gulbenkian de Ciência,

R. Quinta Grande 6, Ap. 14,

2781-901 Oeiras, Portugal

e-mail: avicente@igc.gulbenkian.pt

M. Martins - C. Correia - A. M. Vicente

Instituto Nacional de Saúde Dr. Ricardo Jorge,

Av. Padre Cruz, 1649-016 Lisbon, Portugal

T. Morgadinho

Departamento de Farmacologia, Faculdade de Medicina

da Universidade de Coimbra, R. Larga,

3004-504 Coimbra, Portugal

C. Bento · C. Marques · G. Oliveira

Hospital Pediátrico de Coimbra, Av. Bissaya Barreto,

3000-076 Coimbra, Portugal
}

A. Ataíde - T. S. Miguel

Direcção Regional de Educação da Região Centro,

R. General Humberto Delgado 319,

3030-327 Coimbra, Portugal

\section{J. H. Moore}

Computational Genetics Laboratory,

Department of Genetics, Dartmouth Medical School,

Lebanon, NH 03756, USA didate genes in the serotonin metabolic and neurotransmission pathways and mapping to autism linkage regions (SLC6A4, HTR1A, HTR1D, HTR2A, HTR5A, TPH1 and ITGB3) was analyzed in a sample of 186 nuclear families. The impact of interactions among these genes in autism was assessed using the multifactor-dimensionality reduction (MDR) method in 186 patients and 181 controls. We further evaluated whether the effect of specific gene variants or gene interactions associated with autism etiology might be mediated by their influence on serotonin levels, using the quantitative transmission disequilibrium test (QTDT) and the restricted partition method (RPM), in a sample of 109 autistic children. We report a significant main effect of the HTR5A gene in autism $(P=0.0088)$, and a significant threelocus model comprising a synergistic interaction between the ITGB3 and SLC6A4 genes with an additive effect of HTR5A $(P<0.0010)$. In addition to the previously reported contribution of $S L C 6 A 4$, we found significant associations of ITGB3 haplotypes with serotonin level distribution $(P=0.0163)$. The most significant models contributing to serotonin distribution were found for interactions between TPH1 rs4537731 and SLC6A4 haplotypes $(P=0.002)$ and between HTR1D rs6300 and SLC6A4 haplotypes $(P=0.013)$. In addition to the significant independent effects, evidence for interaction between SLC6A4 and ITGB3 markers was also found. The overall results implicate $S L C 6 A 4$ and ITGB3 gene interactions in autism etiology and in serotonin level determination, providing evidence for a common underlying genetic mechanism and a molecular explanation for the association of platelet hyperserotonemia with autism. 


\section{Introduction}

Autism (AD; OMIM 209850) is a heritable complex neurodevelopmental disorder characterized by impairments in social interaction and communication, and restricted and stereotyped patterns of interests and behaviors (Lord et al. 2000). Although the etiology of autism is not understood, several lines of evidence indicate that the serotonin (5-HT) system may play an important role. Serotonin is a monoamine neurotransmitter involved in the regulation of biological functions such as emotional behavior, sleep, pain sensitivity and hormone release, and plays a crucial role in synaptogenesis and brain development. One of the few consistent findings in autism is platelet hyperserotonemia in a proportion of patients. Platelet serotonin levels have been shown to be highly heritable, both in healthy and in autistic individuals (Abney et al. 2001; Ober et al. 2001; Coutinho et al. 2004). It is therefore plausible that the increased serotonin levels found in autism are genetically determined, and thus the quantification in platelets reflects the levels both in the mature central nervous system (CNS) and during development, at times when the brain may be particularly sensitive to abnormal neurotransmitter function. Increased levels of 5-HT and/or anomalous transmission during the prenatal and early postnatal period are hypothesized to result in abnormal synaptogenesis and brain development, with consequent behavioral manifestations that could be variable according to the brain area affected and to the timing of the insult, and which would persist throughout life in autistic individuals (Whitaker-Azmitia 2005). The genetic factors determining serotonin levels have not been fully established, but are likely candidate genes for autism etiology that can be identified as quantitative trait loci (QTLs) for serotonin levels and confirmed as autism susceptibility factors.

Multiple molecules involved in serotonin metabolism and neurotransmission are known to or have the capacity to regulate serotonin levels in the brain, and are often targets for genetic and pharmacological studies in autism. Some of these molecules are encoded by genes mapping to autism linkage regions. For instance, the serotonin transporter gene $S L C 6 A 4$ and the gene encoding the integrin $\beta 3$ subunit $I T G B 3$, which were both identified as QTLs for serotonin levels (Weiss et al. 2004, 2005a), are located on 17q11.1-q12 and 17q21.32, respectively, under two linkage peaks for autism (Stone et al. 2004; Cantor et al. 2005). The serotonin receptor genes $H T R 2 A$ on $13 \mathrm{q} 14-\mathrm{q} 21$ and HTR $5 A$ on $7 \mathrm{q} 36.1$, also map to regions identified by linkage screens for autism (Barrett et al. 1999; Brad- ford et al. 2001; Alarcón et al. 2002; Auranen et al. 2002). The SLC6A4 gene has received particular attention, chiefly because the serotonin transporter is a target for selective serotonin reuptake inhibitor (SSRI) drugs that are effective in neuropsychiatric disorders. Various groups have reported the association of polymorphic markers within this gene with autism, including an insertion/deletion polymorphism in the promoter that regulates the serotonin reuptake rate (Lesch et al. 1996); however, the associated alleles were often not consistent among studies, and the results were not replicated in several other population samples (Devlin et al. 2005). In a previous study, we have shown that abnormally high platelet 5-HT levels in autistic children are partly explained by genetic variants in $S L C 6 A 4$, although an association of this gene with autism could not be established in our population sample (Coutinho et al. 2004). This suggests that while SLC6A4 could act as a major gene, other genes are very likely interacting with it in the determination of hyperserotonemia associated with autism. The observations were consistent with reported differences in narrow and broad heritability of 5-HT level estimates which suggest that more than one gene is influencing this trait in a nonadditive manner (Abney et al. 2001; Ober et al. 2001), and with the recent genome-wide scan results for whole blood 5-HT, which identified two QTLs on $17 \mathrm{q}$, SLC6A4 and ITGB3. Several other genes encoding molecules involved in the 5-HT system are plausible candidates for a role in the determination of serotonin levels. The 5-HT autoreceptors 5-HT1A and 5-HT1D play an inhibitory role in 5-HT neurotransmission, while a reduced number of platelet 5-HT2A binding sites is present in autistic children with high 5-HT levels and their parents (McBride et al. 1989; Cook et al. 1993), suggesting the involvement of specific variants of the genes encoding these receptors in hyperserotonemia in autistic patients. The 5-HT5A receptor gene HTR5A is mainly expressed in the CNS, also suggesting an important role in mediating the central effects of 5-HT. Tryptophan hydroxylase 1 (TPH1), which catalyzes the ratelimiting step in the synthesis of 5-HT, is located both in the periphery and in the CNS (Zill et al. 2005), and therefore alterations in the TPH1 gene may be involved in any phenotype resulting from a dysfunction of the 5-HT system.

The multiplicity of possible players in the regulation of serotonin levels indicates that interactions between genes, or epistasis, are important in the definition of this phenotype. Epistasis is thought to occur to allow genetic buffering, i.e., to stabilize a phenotype through the requirement that several genes in a gene network 
are mutated before a substantial effect on the phenotype takes place. It is therefore likely that epistasis is a ubiquitous component of the genetic architecture of complex traits, in which the correlations between genotype and phenotype are usually nonlinear not only because of genetic heterogeneity but also due to geneenvironment and gene-gene interactions (Ritchie et al. 2001; Moore 2003b, 2005; Thornton-Wells et al. 2004). It is conceivable if not likely that epistasis in the absence of detectable independent effects of any gene may impact on a phenotype, thus significantly hampering the power of current statistical genetics methods to uncover the genetic basis of complex traits. A research approach that takes into account gene interactions may therefore be a more useful strategy for this purpose.

In the present study, we analyzed the role in autism etiology of seven candidate genes in the serotonin metabolic and neurotransmission pathways and searched for the occurrence of epistatic effects among them. For this purpose, we focused on genes with an established biological role in the serotonin pathway that were located near linkage peaks for autism or had been reported to influence serotonin level distribution, and selected mainly functional polymorphisms that might regulate serotonin levels. We further evaluated whether the impact of specific gene variants and gene interactions in autism etiology might be mediated by their influence on serotonin levels, thus seeking a better understanding of the importance of serotonin levels for the pathophysiology of this disorder and eventually for autism treatment.

\section{Materials and methods}

\section{Subjects and clinical assessments}

One hundred and eighty six autistic patients and their parents were recruited at the Hospital Pediátrico de Coimbra (HP), originating from mainland Portugal $(N=171)$ and the Azorean islands $(N=15)$. The male-to-female ratio was of $4.8: 1$, and the age ranged from 2 to 18 years (mean 6.8 years). Patients were diagnosed using DSM-IV criteria (American Psychiatric Association 1994), the Autism Diagnostic Interview-Revised (ADI-R) (Lord et al. 1994) and the Childhood Autism Rating Scale (CARS) (Schopler et al. 1988). Idiopathic subjects were included after clinical assessment and screening for known medical and genetic associated conditions. Neuropsychological evaluation was performed using the Ruth Griffiths
Mental Developmental Scale II (Griffiths 1984) or the Wechsler Intelligence Scale for Children (WISC 1974). Control adults consisted of 181 unrelated healthy blood donors (male:female ratio of 3.9:1) with no family history of neuropsychiatric diseases, recruited at the Centro Regional de Sangue de Lisboa and at the Hospital Egas Moniz. Control children consisted in 38 unrelated healthy individuals (male:female ratio of 1.3:1), recruited at the HP. The study was approved by the HP ethical committee, and all participants or legal representatives signed an informed consent.

\section{Measurement of platelet serotonin levels}

Platelet serotonin content was measured by high performance liquid chromatography (HPLC) in 109 autistic patients and their parents, as previously described (Coutinho et al. 2004). Serotonin levels were analyzed in subjects free of medication. In a previous study (Coutinho et al. 2004), we found no correlation of platelet serotonin levels with sex or age, and therefore these parameters were not used as covariates in the present analysis.

\section{Genotyping}

A blood sample from the patients, their parents, and control individuals was used for DNA extraction by salting out (Lahiri and Nurnberger 1991). Genotyping of polymorphisms in SLC6A4, HTR2A, HTR1D, HTR $2 A, H T R 5 A$, and TPH1 was based on previously described methods (see Supplementary Table S1). Two polymorphisms in the HTR1A gene (see Supplementary Table S1), were genotyped through the Amplifluor System $^{\mathrm{TM}}$ (KBiosciences, UK) or by PCR-RFLP through insertion of a restriction site, as follows. The PCR $\left(30\right.$ cycles at $94^{\circ} \mathrm{C}$ for $30 \mathrm{~s}, 57^{\circ} \mathrm{C}$ for $30 \mathrm{~s}$, and $72^{\circ} \mathrm{C}$ for $30 \mathrm{~s}$ ) was performed with $25 \mathrm{ng}$ of genomic DNA, $200 \mu \mathrm{M}$ of each dNTP (Promega), $2 \mathrm{mM}$ of $\mathrm{MgCl}_{2}$ (Promega), $1 \times$ PCR buffer (Promega), $1.5 \mathrm{U}$ of Taq polymerase, and $0.4 \mu \mathrm{M}$ of each primer (final volume of $12.5 \mu \mathrm{l}$ ). For rs6295 and rs878567, the polymorphisms were detected by restriction with TaqI (Roche) and ApeKI (New England Biolabs), respectively, according to the manufacturer's instructions, and resolved by electrophoresis in a $2.5 \%$ conventional agarose gel. Two polymorphisms in ITGB3 (see Supplementary Table S1) were genotyped as follows. For rs5918, the PCR $\left(30\right.$ cycles at $94^{\circ} \mathrm{C}$ for $30 \mathrm{~s}, 60^{\circ} \mathrm{C}$ for $30 \mathrm{~s}$, and $72^{\circ} \mathrm{C}$ for $30 \mathrm{~s}$ ) was performed with $37.5 \mathrm{ng}$ of genomic DNA, $200 \mu \mathrm{M}$ of each dNTP (Promega), $2 \mathrm{mM}$ of $\mathrm{MgCl}_{2}$ (Promega), $1 \times$ PCR buffer (Promega), 
$1.5 \mathrm{U}$ of Taq polymerase, and $0.36 \mu \mathrm{M}$ of each primer (final volume of $12.5 \mu \mathrm{l}$ ). For rs15908, the PCR (30 cycles at $94^{\circ} \mathrm{C}$ for $30 \mathrm{~s}, 57^{\circ} \mathrm{C}$ for $30 \mathrm{~s}$, and $72^{\circ} \mathrm{C}$ for $30 \mathrm{~s}$ ) was performed with $37.5 \mathrm{ng}$ of genomic DNA, $200 \mu \mathrm{M}$ of each dNTP (Promega), $2 \mathrm{mM}$ of $\mathrm{MgCl}_{2}$ (Promega), $1 \times$ PCR buffer (Promega), 1.5 U of Taq polymerase, and $1.2 \mu \mathrm{M}$ of each primer (final volume of $12.5 \mu \mathrm{l}$ ). For rs5918 and rs15908, the polymorphisms were detected by restriction with HpaII (Fermentas) and TaqI (Roche) respectively, according to the manufacturer's instructions, and resolved by electrophoresis in a $2 \%$ conventional agarose gel.

\section{Statistical analysis}

The effects of each marker in association with autism etiology were assessed using the Extended Transmission Disequilibrium Test (ETDT, version 2.4) for individual markers (Sham and Curtis 1995) and TRANSMIT (Clayton 1999), version 2.5.2, for haplotypes. Testing for genetic interactions in association with autism was performed using the multifactordimensionality reduction (MDR) method (Ritchie et al. 2001; Moore 2004), version beta 1.0.0 RC1, available from http://www.epistasis.org/mdr.html. The details of the MDR method have been presented elsewhere (Ritchie et al. 2001; Moore 2004; Moore et al. 2006). Briefly, a set of $n$ polymorphisms are selected. The $n$ polymorphisms and their possible multilocus classes are represented in $n$-dimensional space; for example, for two loci with three genotypes each, there are nine possible two-locus genotype combinations. Then, the ratio for the number of cases to the number of controls is calculated within each multilocus class. Each multilocus class in $n$-dimensional space is then labeled as "high-risk" if the cases to controls ratio meets or exceeds some threshold (e.g., $\geq 1$ ), or as "low-risk" if that threshold is not exceeded; the method thus reduces the $n$-dimensional space to one dimension with two levels ("low-risk" and "high-risk"). The process of creating a new variable as a function of two or more variables is called constructive induction (Moore et al. 2006). This new single MDR variable is assessed for its ability to classify subjects as sick or healthy using a naïve Bayes classifier. All possible combinations of polymorphisms are evaluated and the best selected as the model that is most likely to generalize to independent datasets as assessed by estimating a testing balanced accuracy (TBA) with ten-fold cross-validation. Balanced accuracy is defined as the arithmetic mean of sensitivity and specificity:

$$
\begin{gathered}
1 / 2(\mathrm{TP} / \mathrm{TP}+\mathrm{FN}+\mathrm{TN} / \mathrm{TN}+\mathrm{TP}) \\
=(\text { sensitivity }+ \text { specificity }) / 2
\end{gathered}
$$

where $\mathrm{TP}$ are true positives, $\mathrm{TN}$ are true negatives, and FN are false negatives (Velez et al. 2006). Cross validation divides the data into a training set and a testing set in order to assess generalizability (Coffey et al. 2004). With ten-fold cross validation, the data are divided into ten equal parts, and the model is developed on $9 / 10$ of the data (training set) and then tested on 1/ 10 of the remaining data (testing set). This is repeated for each possible $9 / 10$ and $1 / 10$ of the data, and the resulting ten testing accuracies averaged (Hastie et al. 2001). In addition to the testing accuracy, we also report the cross validation consistency (CVC) that is a measure of how many times out of ten divisions of the data that MDR found the same best model (Moore 2003a). Models that are true positives are likely to generalize to independent datasets and will have estimated testing accuracies of greater than 0.5. Permutation testing was performed to assess the probability of obtaining a testing accuracy as large or larger than observed in the original data given the null hypothesis of no association is true. This is carried out by randomizing the case-control labels 1,000 times and repeating the MDR analysis on each randomized dataset. This process yields an empirical distribution of testing balanced accuracies under the null hypothesis that is in turn used to calculate a $P$ value. Permutation testing is important to correct for multiple testing (Good 2000). MDR was run for models with two and three marker combinations between the individual markers or haplotypes. Missing genotypes were imputed with MDR data tool software (beta version 0.4.3), which allows the global replacement of unknown values and the imputation of the data from a model constructed by the software from the existing dataset. Unknown haplotypes were estimated with the program PHASE (Stephens et al. 2001), version 2.1.1. The population sample used for the MDR test consisted of 186 autistic children and 181 healthy adult controls. Using approximately the same number of cases and controls allows for an increase in power; for this analysis, the ratio cases/controls was 1.03 . Genotypic combinations for which the ratio cases/controls was equal to 1.03 were set to be classified as unknown risk. The models presenting the maximum TBA were selected as the best MDR models.

To confirm, visualize, and interpret the genetic interactions identified, MDR allows the construction of interaction dendograms (Moore et al. 2006). This graph plots the interactions between the variables 
tested (determined by interaction entropy analysis) in hierarchical clustering, placing the most strongly interacting variables close together at the leaves of the tree. Interaction entropy is a measure of information gain (i.e., percentage of entropy removed) on casecontrol status from merging two variables together over that provided by the two variables independently. Additive and nonadditive interactions, as well as redundancy, can thus be easily visualized and used to interpret the MDR models.

Statistical analysis of platelet 5-HT levels was performed following logarithmic (ln) transformation of the quantitative variable, in order to approach a normal distribution. Analysis with haplotypes was performed only when it was possible to establish phase. To test the main effect of each marker on the 5-HT distribution, quantitative transmission disequilibrium tests (QTDT) were performed, implemented in the QTDT software, version 2.4.6 (Abecasis et al. 2000). The orthogonal model of association was considered, including variance components (individual and nuclear family environment and a polygenic component). This test, based on maximum-likelihood estimates, allows variance components testing of family-based samples for association and transmission disequilibrium, estimating the relative weight of each contributor to the phenotype. Association is partitioned into betweenand within-family components, the test for the latter being free of confounding population substructure effects, regardless of the nuclear family composition. The broad heritability of platelet serotonin levels was determined using QTDT, by testing the significance of the polygenic variance component of the trait distribution; a null model including solely an environmental component of variance was compared to a full model including this and a polygenic variance component. Genetic interactions in the determination of platelet 5HT levels were tested using the restricted partition method (RPM) (Culverhouse et al. 2004), in a sample of 109 autistic children and 38 age-matched controls. RPM is a model-free method for detecting and characterizing nonadditive interactions among discrete genetic and environmental factors that contribute to quantitative trait variation. The goal of RPM is to find partitions of multilocus genotypes that explain a significant proportion of the observed trait variation. For each model, a coefficient of determination $\left(R^{2}\right)$ is estimated for the quantitative trait value regressed on the final genotype groups, and is a measure of the proportion of the total variance explained by the groups of the respective model. We ran RPM for twoway interactions between the 11 individual markers and haplotypes, in a total of 97 tests performed. The significance of each model was validated with 9,700 permutations, according to the number of tests (number of permutations $=[1 /(0.05 /$ number of tests $)] \times 5)$, in order to generate a large enough empirical null distribution to yield a $P$ value with the desired precision $(\alpha=0.05)$. In the permutation test, the data trait values are randomized and, for each permutated data, RPM is performed and the $R^{2}$ is estimated. The significance of each model is assessed by the frequency with which the $R^{2}$ from the original data exceeds the permutated $R^{2}$ values. Only groups with more than one individual were considered in the analysis. Due to the small sample size, no more than two-way interactions were tested.

\section{Results}

To assess individual contributions of each marker in autism etiology, the TDT was carried out for 11 individual markers in the seven candidate genes and their respective haplotypes (Tables 1,2). A significant main effect in autism was found for HTR5A rs 1800883 marker $(P=0.0088)$, with allele $-19 \mathrm{G}$ significantly overtransmitted to the autistic probands (Table 1). A specific haplotype of HTR $5 A$ markers containing the undertransmitted $-19 \mathrm{C}$ allele was significantly less transmitted than expected $(P=0.0333)$ (Table 2). No significant associations were found with other individual markers or haplotypes.

The MDR method was used to assess the impact of two- and three-way combinations between the 11 individual markers in autism etiology (Table 3). The best two-marker model selected by MDR was an interaction between SLC6A4 intron 2 VNTR and ITGB3 rs5918, with a maximum testing balanced accuracy (TBA) of 0.6357 , thus being able to classify correctly $64 \%$ of the individuals used in the analysis $(P<0.001)$, and with a cross-validation consistency (CVC) of 6/10. The best three-marker model identified included these two markers and added HTR5A rs6320, increasing the TBA to $67 \%(P<0.001)$, and with a CVC of 4/10. A two-way model between SLC6A4 and ITGB3 marker haplotypes was also significant, with a TBA of $0.5853(P=0.020)$, but with a CVC of $9 / 10$. The best three-way marker haplotype model again included markers in SLC6A4, ITGB3, and HTR5A (TBA $=0.6066, P=0.009$ and CVC of $10 / 10$ ). This indicates that interaction between genetic variants at $S L C 6 A 4$ and ITGB3 genes is associated with increased risk for autism, a finding compatible with the linkage peaks for autism on chromosome $17 \mathrm{q}$, in the regions where these genes map (Stone et al. 2004; Cantor et al. 
Table 1 Transmission disequilibrium test results (ETDT analysis), to assess the main effects of each marker in association with autism etiology

\begin{tabular}{|c|c|c|c|c|c|}
\hline Marker & Allele & $\mathrm{T}$ & NT & $\chi^{2}(d f)$ & $P$ value \\
\hline TPH1 rs4537731 & $\begin{array}{l}-6526 \mathrm{G} \\
-6526 \mathrm{~A} \\
\text { Global test }\end{array}$ & $\begin{array}{l}85 \\
82\end{array}$ & $\begin{array}{l}82 \\
85\end{array}$ & $\begin{array}{l}0.054(1) \\
0.054(1) \\
0.054(1)\end{array}$ & $\begin{array}{l}0.8164 \\
0.8164 \\
0.8164\end{array}$ \\
\hline HTR2A rs6311/rs6313 & $\begin{array}{l}-1438 \mathrm{~A} / 102 \mathrm{~T} \\
-1438 \mathrm{G} / 102 \mathrm{C} \\
\text { Global test }\end{array}$ & $\begin{array}{l}72 \\
71\end{array}$ & $\begin{array}{l}71 \\
72\end{array}$ & $\begin{array}{l}0.007(1) \\
0.007(1) \\
0.007(1)\end{array}$ & $\begin{array}{l}0.9334 \\
0.9334 \\
0.9333\end{array}$ \\
\hline$H T R 1 D$ rs6300 & $\begin{array}{l}1080 \mathrm{~T} \\
1080 \mathrm{C} \\
\text { Global test }\end{array}$ & $\begin{array}{l}33 \\
26\end{array}$ & $\begin{array}{l}26 \\
33\end{array}$ & $\begin{array}{l}0.831(1) \\
0.831(1) \\
0.832(1)\end{array}$ & $\begin{array}{l}0.3622 \\
0.3622 \\
0.3616\end{array}$ \\
\hline SLC6A4 5-HTTLPR & $\begin{array}{l}\mathrm{L} \\
\mathrm{S} \\
\text { Global test }\end{array}$ & $\begin{array}{l}71 \\
71\end{array}$ & $\begin{array}{l}71 \\
71\end{array}$ & $\begin{array}{l}0.000(1) \\
0.000(1) \\
0.000(1)\end{array}$ & $\begin{array}{l}1.0000 \\
1.0000 \\
1.0000\end{array}$ \\
\hline SLC6A4 intron $2 \mathrm{VNTR}$ & $\begin{array}{l}\text { Stin2.9 } \\
\text { Stin2.10 } \\
\text { Stin2.12 } \\
\text { Global test }\end{array}$ & $\begin{array}{l}2 \\
70 \\
53\end{array}$ & $\begin{array}{l}1 \\
52 \\
72\end{array}$ & $\begin{array}{l}\text { not tested } \\
2.656(1) \\
2.888(1) \\
3.005(2)\end{array}$ & $\begin{array}{l}0.1032 \\
0.0893 \\
0.2226\end{array}$ \\
\hline$I T G B 3$ rs5918 & $\begin{array}{l}\text { Leu33 } \\
\text { Pro33 } \\
\text { Global test }\end{array}$ & $\begin{array}{l}43 \\
35\end{array}$ & $\begin{array}{l}35 \\
43\end{array}$ & $\begin{array}{l}0.821(1) \\
0.821(1) \\
0.822(1)\end{array}$ & $\begin{array}{l}0.3651 \\
0.3651 \\
0.3647\end{array}$ \\
\hline ITGB3 rs15908 & $\begin{array}{l}1143 \mathrm{~A} \\
1143 \mathrm{C} \\
\text { Global test }\end{array}$ & $\begin{array}{l}67 \\
76\end{array}$ & $\begin{array}{l}76 \\
67\end{array}$ & $\begin{array}{l}0.566(1) \\
0.566(1) \\
0.567(1)\end{array}$ & $\begin{array}{l}0.4517 \\
0.4517 \\
0.4516\end{array}$ \\
\hline HTR1A rs6295 & $\begin{array}{l}-1019 \mathrm{C} \\
-1019 \mathrm{G} \\
\text { Global test }\end{array}$ & $\begin{array}{l}88 \\
82\end{array}$ & $\begin{array}{l}82 \\
88\end{array}$ & $\begin{array}{l}0.212(1) \\
0.212(1) \\
0.212(1)\end{array}$ & $\begin{array}{l}0.6454 \\
0.6454 \\
0.6454\end{array}$ \\
\hline$H T R 1 A$ rs878567 & $\begin{array}{l}1556 \mathrm{~T} \\
1556 \mathrm{C} \\
\text { Global test }\end{array}$ & $\begin{array}{l}81 \\
90\end{array}$ & $\begin{array}{l}90 \\
81\end{array}$ & $\begin{array}{l}0.474(1) \\
0.474(1) \\
0.474(1)\end{array}$ & $\begin{array}{l}0.4913 \\
0.4913 \\
0.4912\end{array}$ \\
\hline HTR5A rs1800883 & $\begin{array}{l}-19 \mathrm{G} \\
-19 \mathrm{C} \\
\text { Global test }\end{array}$ & $\begin{array}{l}81 \\
51\end{array}$ & $\begin{array}{l}51 \\
81\end{array}$ & $\begin{array}{l}6.818(1) \\
6.818(1) \\
6.878(1)\end{array}$ & $\begin{array}{l}0.0091 \\
0.0091 \\
0.0088\end{array}$ \\
\hline$H T R 5 A$ rs 6320 & $\begin{array}{l}12 \mathrm{~A} \\
12 \mathrm{~T} \\
\text { Global test }\end{array}$ & $\begin{array}{l}74 \\
69\end{array}$ & $\begin{array}{l}69 \\
74\end{array}$ & $\begin{array}{l}0.175(1) \\
0.175(1) \\
0.175(1)\end{array}$ & $\begin{array}{l}0.6759 \\
0.6759 \\
0.6758\end{array}$ \\
\hline
\end{tabular}

$T$ transmitted, $N T$ not transmitted

2005). Three-way genetic combinations between these two genes and HTR5A are also associated with increased risk for autism, in agreement with the main effect in autism found for HTR5A in this sample (see Supplementary Table S2 for a detailed description of the genotypic combinations associated with high- and low-risk for autism for the MDR best models).

The interaction dendograms shown in Fig. 1a, b allow a better interpretation of the genetic effects identified by MDR. As expected, the strongest synergy among individual markers (Fig. 1a, line 1) was found between SLC6A4 intron 2 VNTR and ITGB3 rs5918, indicative of a nonadditive effect. Synergy was moderate for markers HTR1A rs6295 and HTR5A rs6320 (Fig. 1a, line 2); however, this model was not good in predicting disease-risk status for autism (CVC of 0/10), and was not selected by the MDR analysis. Impor- tantly, the Fig. 1a interaction dendogram shows that for the best three-marker model associated with autism, SLC6A4 intron 2 VNTR and ITGB3 rs5918 act synergistically but HTR5A rs6320 contributes with an additive effect to the model (Fig. 1a, line 3). This interpretation is consistent with the individual association of HTR5A with autism. Figure $1 \mathrm{~b}$ corroborates these results, displaying a strong synergy between SLC6A4 and ITGB3 marker haplotypes (line 1) but an additive effect of HTR5A haplotypes (line 3 ).

Our sample provides a very significant evidence of a polygenic component $\left(P=5 \times 10^{-7}\right)$ for platelet serotonin levels, for which the broad heritability was estimated at $64 \%$. The individual contributions of candidate gene marker alleles and haplotypes to platelet serotonin levels in autistic children were assessed using QTDT. In addition to the previously re- 
Table 2 Transmission disequilibrium test results (TRANSMIT analysis), to assess the main effects of each marker haplotype in association with autism etiology

\begin{tabular}{|c|c|c|c|c|c|}
\hline Marker & Haplotype & Observed & Expected & $\chi^{2}(d f)$ & $P$ value \\
\hline SLC6A4 5-HTTLPR/intron 2 VNTR & $\begin{array}{l}\text { L/Stin2.9 } \\
\text { S/Stin2.9 } \\
\text { L/Stin2.10 } \\
\text { S/Stin2.10 } \\
\text { L/Stin2.12 } \\
\text { S/Stin2.12 } \\
\text { Global test }\end{array}$ & $\begin{array}{r}3.144 \\
0.045 \\
98.052 \\
35.701 \\
82.287 \\
120.770\end{array}$ & $\begin{array}{r}1.654 \\
0.563 \\
88.320 \\
34.560 \\
90.952 \\
123.950\end{array}$ & $\begin{array}{l}2.961(1) \\
1.074(1) \\
3.304(1) \\
0.107(1) \\
2.568(1) \\
0.295(1) \\
8.502(5)\end{array}$ & $\begin{array}{l}0.0853 \\
0.3000 \\
0.0691 \\
0.7440 \\
0.1090 \\
0.5868 \\
0.1306\end{array}$ \\
\hline ITGB3 rs5918/rs15908 & $\begin{array}{l}\text { Leu33/1143A } \\
\text { Pro33/1143A } \\
\text { Leu33/1143C } \\
\text { Pro33/1143C } \\
\text { Global test }\end{array}$ & $\begin{array}{r}169.860 \\
5.142 \\
87.142 \\
35.858\end{array}$ & $\begin{array}{r}171.110 \\
5.945 \\
80.438 \\
40.510\end{array}$ & $\begin{array}{l}0.045(1) \\
0.234(1) \\
1.546(1) \\
1.259(1) \\
2.332(3)\end{array}$ & $\begin{array}{l}0.8325 \\
0.6285 \\
0.2137 \\
0.2618 \\
0.5065\end{array}$ \\
\hline HTR1A rs6295/rs878567 & $\begin{array}{l}-1019 \mathrm{C} / 1556 \mathrm{~T} \\
-1019 \mathrm{G} / 1556 \mathrm{~T} \\
-1019 \mathrm{C} / 1556 \mathrm{C} \\
-1019 \mathrm{G} / 1556 \mathrm{C} \\
\text { Global test }\end{array}$ & $\begin{array}{r}3.508 \\
160.760 \\
185.160 \\
10.570\end{array}$ & $\begin{array}{r}6.119 \\
162.570 \\
180.540 \\
10.767\end{array}$ & $\begin{array}{l}2.478(1) \\
0.075(1) \\
0.494(1) \\
0.011(1) \\
3.751(3)\end{array}$ & $\begin{array}{l}0.1155 \\
0.7842 \\
0.4821 \\
0.9159 \\
0.2897\end{array}$ \\
\hline HTR5A rs1800883/rs6320 & $\begin{array}{l}-19 \mathrm{G} / 12 \mathrm{~A} \\
-19 \mathrm{C} / 12 \mathrm{~A} \\
-19 \mathrm{G} / 12 \mathrm{~T} \\
-19 \mathrm{C} / 12 \mathrm{~T} \\
\text { Global test }\end{array}$ & $\begin{array}{r}104.150 \\
4.501 \\
142.900 \\
94.446\end{array}$ & $\begin{array}{r}102.110 \\
4.186 \\
132.490 \\
107.210\end{array}$ & $\begin{array}{l}0.120(1) \\
0.056(1) \\
2.551(1) \\
4.532(1) \\
4.825(3)\end{array}$ & $\begin{array}{l}0.7286 \\
0.8127 \\
0.1102 \\
0.0333 \\
0.1851\end{array}$ \\
\hline
\end{tabular}

Table 3 Best models assessed by the MDR method for two-way and three-way combinations, to test for epistasis in association with autism etiology

\begin{tabular}{|c|c|c|c|c|c|c|}
\hline \multirow{2}{*}{$\begin{array}{l}\mathrm{Nb} . \\
\text { markers }\end{array}$} & \multicolumn{3}{|l|}{ Best models } & \multirow{2}{*}{$\begin{array}{l}\text { Cross-validation } \\
\text { consistency }\end{array}$} & \multirow{2}{*}{$\begin{array}{l}\text { Testing balanced } \\
\text { accuracy (Empirical } \\
P \text { value) }\end{array}$} & \multirow{2}{*}{$\begin{array}{l}\text { Odds-ratio } \\
\text { (95\% Confidence } \\
\text { Interval) }\end{array}$} \\
\hline & Marker 1 & Marker 2 & Marker 3 & & & \\
\hline 2 & $\begin{array}{l}\text { SLC6A4 intron } \\
2 \text { VNTR }\end{array}$ & $I T G B 3$ rs5918 & & $6 / 10$ & $0.6357(<0.001)$ & $3.24(2.12-4.97)$ \\
\hline 2 & TPH1 rs4537731 & $H T R 5 A$ rs6320 & & $4 / 10$ & $0.6348(<0.001)$ & $3.36(2.18-5.17)$ \\
\hline 3 & $\begin{array}{l}S L C 6 A 4 \text { intron } \\
2 \text { VNTR }\end{array}$ & ITGB3 rs5918 & $H T R 5 A$ rs6320 & $4 / 10$ & $0.6676(<0.001)$ & $4.84(3.11-7.54)$ \\
\hline 3 & $\begin{array}{l}H T R 2 A \\
\quad \text { rs } 6311 / \mathrm{rs} 6313\end{array}$ & $\begin{array}{l}S L C 6 A 4 \text { intron } \\
2 \text { VNTR }\end{array}$ & $H T R 5 A$ rs6320 & $4 / 10$ & $0.6462(<0.001)$ & $4.68(3.01-7.27)$ \\
\hline
\end{tabular}

ported contribution of SLC6A4 haplotypes (Coutinho et al. 2004), we found significant associations of ITGB3 rs5918 marker and rs5918/rs15908 haplotypes with serotonin level distribution (Table 4). The rs5918 marker allele Pro33 was positively associated with 5-HT levels in autistic children $(P=0.0055)$, accounting for $16.9 \%$ of the phenotypic variance, replicating previous findings of an association of this allele with 5-HT levels towards the high end of the distribution in a healthy population (Weiss et al. 2004, 2005a, 2005b). A significant global association was also observed for ITGB3 rs5918/rs15908 haplotypes $(P=0.0163)$, with haplotype Pro33/1143C showing a significant positive association with the trait $(P=0.0019)$. The proportion of variance accounted for by this haplotype, estimated at $24.5 \%$, was increased in relation to the independently associated rs5918 marker. Altogether, these results demonstrate significant main individual effects of SLC6A4 and ITGB3 in the determination of platelet 5-HT levels, which account for a significant proportion of the genetic trait variation in an autistic population. No associations were found with the remaining markers tested.

Interaction effects among the candidate gene markers contributing to the determination of 5-HT levels were modeled using RPM. Interactions were tested for all possible two-way marker and haplotype combinations, and are shown in Table 5 (see Supplementary Table S3 for detailed information about the genotypic combinations of the significant RPM 
Fig. 1 Interaction

dendograms for the markers tested in the MDR analysis for association with autism. a Interactions between the 11 individual markers, clearly showing a strong synergistic effect (epistasis) between $S L C 6 A 4$ intron 2 VNTR and ITGB3 rs5918 (line 1); weaker synergy is found between HTR1A rs6295 and HTR5A rs6320 (line 2); redundancy is found for TPH1 rs4537731 and HTR1A rs878567 markers (line 4); additivity lines (line 3) confirm the independent effect of the HTR5A rs6320 marker over $S L C 6 A 4$ intron 2 VNTR and ITGB3 rs5918. b Interactions between haplotypes, where the strong synergy between $S L C 6 A 4$ and $I T G B 3$ and the additive effect of HTR5A with these two genes are confirmed; redundancy between markers is shown by lines 4 and 5 a
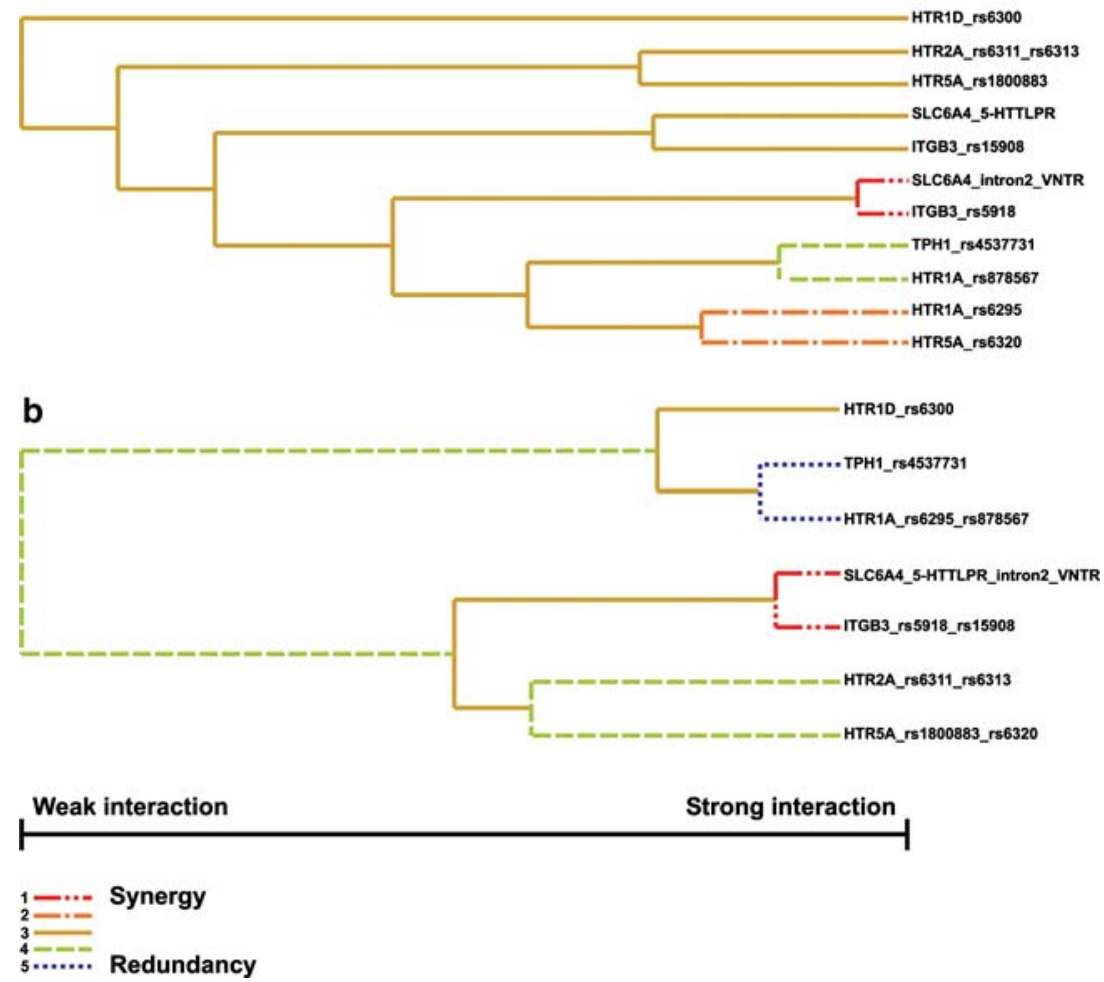

models). The analysis was restricted to two-way combinations because, given the present sample size, when testing higher-order interactions we would expect many two-locus genotypes to be void or have very few observations. The most significant models contributing to 5-HT distribution were found for interactions between TPH1 rs4537731 and SLC6A4 haplotypes $(P=0.002)$ and between HTR1D rs6300 and SLC6A4 haplotypes $(P=0.013)$. Most interestingly, interactions between $S L C 6 A 4$ haplotypes and the ITGB3 markers rs5918 $(P=0.037)$ and $\operatorname{rs} 15908(P=0.035)$ also significantly contribute to trait distribution. Interaction between marker haplotypes in both genes was not significant, likely because the number of individuals used in the analysis of this particular model was lower $(N=97)$, with a consequent loss of statistical power. Other significant interactions were found in association with 5-HT levels, namely ITGB3 rs5918 with HTR5A rs6320 $(P=0.027)$, and ITGB3 haplotypes with HTR1A haplotypes $(P=0.030)$.

Because we initially hypothesized that a common set of genes or gene interactions might bear an impact in autism by contributing to the determination of 5-HT levels, we tested whether the interaction models identified as contributing the most to serotonin distribution using RPM might also be associated with autism. For this purpose, we analyzed the TBA and CVC of interaction models tested by MDR but not selected as best models. We found that two of the interaction models most significantly contributing to 5-HT distribution were also associated with autism, namely the interaction of TPH1 rs4537731 with SLC6A4 haplotypes $(\mathrm{TBA}=0.5941, P=0.015)$ and the interaction of ITGB3 rs5918 with HTR5A rs6320 (TBA $=0.5923$, $P=0.025)$; however for both these models the CVC was $0 / 10$, and analysis of the corresponding interaction dendograms indicates that there is redundancy and additivity, respectively, between the marker variants. The other interaction models significantly contributing to 5-HT determination were not significantly associated with autism, except for those that included $S L C 6 A 4$ and ITGB3 markers, as already referred.

The overall results therefore consistently implicate the SLC6A4 and ITGB3 genes in autism etiology and in serotonin level determination and show that interaction between the same genetic variants is associated with both traits, strongly suggesting a causal relationship.

\section{Discussion}

The main purpose of the present paper was to further our understanding of the role of serotonin pathway genes in autism. We report a significant main effect of the HTR5A gene in autism, with a significant associa- 
Table 4 QTDT orthogonal tests of association with variance components, to assess the main effects of each marker and respective haplotypes in association with platelet serotonin levels

\begin{tabular}{|c|c|c|c|c|c|}
\hline Marker & Allele & $\chi^{2}(d f)$ & $P$ value & $\begin{array}{l}\text { Direction of } \\
\text { association }\end{array}$ & $\begin{array}{l}\text { Proportion of phenotypic } \\
\text { variance accounted by } \\
\text { each allele/haplotype }(\%)\end{array}$ \\
\hline \multirow{3}{*}{ ITGB3 rs5918 } & Leu33 & $7.71(1)$ & 0.0055 & Negative & 16.9 \\
\hline & Pro33 & $7.71(1)$ & 0.0055 & Positive & 16.9 \\
\hline & Global test & $7.71(1)$ & 0.0055 & & \\
\hline \multirow[t]{3}{*}{ ITGB3 rs15908 } & $1143 \mathrm{~A}$ & $1.57(1)$ & $>0.1$ & & \\
\hline & $1143 \mathrm{C}$ & $1.57(1)$ & $>0.1$ & & \\
\hline & Global test & $1.57(1)$ & 0.2108 & & \\
\hline \multirow[t]{5}{*}{ ITGB3 rs5918/rs15908 } & Leu33/1143A & $2.31(1)$ & $>0.1$ & & \\
\hline & Leu33/1143C & $0.37(1)$ & $>0.1$ & & \\
\hline & Pro33/1143A & Not tested & Not tested & & \\
\hline & Pro33/1143C & $9.68(1)$ & 0.0019 & Positive & 24.5 \\
\hline & Global test & $10.29(3)$ & 0.0163 & & \\
\hline \multirow[t]{3}{*}{ SLC6A4 5-HTTLPR } & $\mathrm{L}$ & $5.72(1)$ & 0.0168 & Positive & 11.2 \\
\hline & $\mathrm{S}$ & $5.72(1)$ & 0.0168 & Negative & 11.2 \\
\hline & Global test & $5.72(1)$ & 0.0168 & & \\
\hline \multirow[t]{3}{*}{$S L C 6 A 4$ intron $2 \mathrm{VNTR}$} & Stin2.10 & $3.92(1)$ & 0.0477 & Positive & 8.3 \\
\hline & Stin2.12 & $3.91(1)$ & 0.0480 & Negative & 8.5 \\
\hline & Global test & $3.95(1)$ & 0.0468 & & \\
\hline \multirow[t]{5}{*}{ SLC6A4 5-HTTLPR/intron 2 VNTR } & L/Stin2.10 & $10.34(1)$ & 0.0013 & Positive & 18.4 \\
\hline & L/Stin2.12 & $0.00(1)$ & $>0.1$ & & \\
\hline & $\mathrm{S} / \mathrm{Stin} 2.10$ & $1.16(1)$ & $>0.1$ & & \\
\hline & S/Stin2.12 & $4.10(1)$ & 0.0429 & Negative & 9.1 \\
\hline & Global test & $12.08(3)$ & 0.0168 & & \\
\hline \multirow[t]{3}{*}{ TPH1 rs4537731 } & $-6526 \mathrm{G}$ & $0.43(1)$ & $>0.1$ & & \\
\hline & $-6526 \mathrm{~A}$ & $0.43(1)$ & $>0.1$ & & \\
\hline & Global test & $0.43(1)$ & 0.5128 & & \\
\hline \multirow[t]{3}{*}{ HTR1A rs6295 } & $-1019 \mathrm{C}$ & $0.66(1)$ & $>0.1$ & & \\
\hline & $-1019 \mathrm{G}$ & $0.66(1)$ & $>0.1$ & & \\
\hline & Global test & $0.66(1)$ & 0.4150 & & \\
\hline \multirow[t]{3}{*}{$H T R 1 A$ rs 878567} & $1556 \mathrm{~T}$ & $0.09(1)$ & $>0.1$ & & \\
\hline & $1556 \mathrm{C}$ & $0.09(1)$ & $>0.1$ & & \\
\hline & Global test & $0.09(1)$ & 0.7687 & & \\
\hline \multirow[t]{5}{*}{ HTR1A rs6295/rs878567 } & $-1019 \mathrm{C} / 1556 \mathrm{~T}$ & Not tested & Not tested & & \\
\hline & $-1019 \mathrm{C} / 1556 \mathrm{C}$ & $0.11(1)$ & $>0.1$ & & \\
\hline & $-1019 \mathrm{G} / 1556 \mathrm{~T}$ & $0.28(1)$ & $>0.1$ & & \\
\hline & $-1019 \mathrm{G} / 1556 \mathrm{C}$ & Not tested & Not tested & & \\
\hline & Global test & $0.68(3)$ & 0.7135 & & \\
\hline \multirow[t]{3}{*}{$H T R 1 D$ rs6300 } & $1080 \mathrm{~T}$ & $0.28(1)$ & $>0.1$ & & \\
\hline & $1080 \mathrm{C}$ & $0.28(1)$ & $>0.1$ & & \\
\hline & Global test & $0.28(1)$ & 0.5941 & & \\
\hline \multirow[t]{3}{*}{$H T R 2 A$ rs6311/rs6313 } & $-1438 \mathrm{~A} / 102 \mathrm{~T}$ & $1.31(1)$ & $>0.1$ & & \\
\hline & $-1438 \mathrm{G} / 102 \mathrm{C}$ & $1.31(1)$ & $>0.1$ & & \\
\hline & Global test & $1.31(1)$ & 0.2523 & & \\
\hline \multirow[t]{3}{*}{ HTR5A rs1800883 } & $-19 \mathrm{G}$ & $0.63(1)$ & $>0.1$ & & \\
\hline & $-19 \mathrm{C}$ & $0.63(1)$ & $>0.1$ & & \\
\hline & Global test & $0.63(1)$ & 0.4279 & & \\
\hline \multirow{3}{*}{ HTR5A rs6320 } & $12 \mathrm{~A}$ & $0.47(1)$ & $>0.1$ & & \\
\hline & $12 \mathrm{~T}$ & $0.47(1)$ & $>0.1$ & & \\
\hline & Global test & $0.47(1)$ & 0.4926 & & \\
\hline \multirow[t]{5}{*}{ HTR5A rs1800883/rs6320 } & $-19 \mathrm{G} / 12 \mathrm{~A}$ & $0.09(1)$ & $>0.1$ & & \\
\hline & $-19 \mathrm{G} / 12 \mathrm{~T}$ & $0.01(1)$ & $>0.1$ & & \\
\hline & $-19 \mathrm{C} / 12 \mathrm{~A}$ & Not tested & $>0.1$ & & \\
\hline & $-19 \mathrm{C} / 12 \mathrm{~T}$ & $0.00(1)$ & $>0.1$ & & \\
\hline & Global test & $1.20(3)$ & 0.7531 & & \\
\hline
\end{tabular}


Table 5 RPM results for two-way interactions, to test for epistasis in the determination of platelet serotonin levels

\begin{tabular}{|c|c|c|c|c|c|}
\hline \multicolumn{2}{|l|}{ Two-way model } & \multirow[t]{2}{*}{$N$} & \multirow[t]{2}{*}{$\mathrm{Nb}$. groups } & \multirow[t]{2}{*}{$R^{2}$} & \multirow{2}{*}{$\begin{array}{l}\text { Empirical } \\
P \text { value }\end{array}$} \\
\hline Marker 1 & Marker 2 & & & & \\
\hline TPH1 rs4537731 & SLC6A4 5-HTTLPR/intron 2 VNTR & 122 & 3 & 0.251 & 0.002 \\
\hline$H T R 1 D$ rs6300 & SLC6A4 5-HTTLPR/intron 2 VNTR & 122 & 2 & 0.161 & 0.013 \\
\hline SLC6A4 5-HTTLPR & $S L C 6 A 4$ intron $2 \mathrm{VNTR}$ & 138 & 2 & 0.099 & 0.018 \\
\hline ТРH1 rs4537731 & SLC6A4 5-HTTLPR & 140 & 2 & 0.097 & 0.019 \\
\hline ITGB3 rs5918 & HTR5A rs6320 & 140 & 2 & 0.070 & 0.027 \\
\hline HTR1A rs6295/rs878567 & ITGB3 rs5918/rs15908 & 95 & 2 & 0.193 & 0.030 \\
\hline ITGB3 rs15908 & SLC6A4 5-HTTLPR/intron 2 VNTR & 115 & 2 & 0.209 & 0.035 \\
\hline$H T R 1 D$ rs6300 & SLC6A4 5-HTTLPR & 139 & 2 & 0.065 & 0.036 \\
\hline ITGB3 rs5918 & SLC6A4 5-HTTLPR/intron 2 VNTR & 122 & 2 & 0.150 & 0.037 \\
\hline SLC6A4 5-HTTLPR & $H T R 5 A$ rs1800883 & 142 & 2 & 0.076 & 0.042 \\
\hline ITGB3 rs15908 & HTR1A rs6295/rs878567 & 106 & 2 & 0.130 & 0.042 \\
\hline HTR1A rs878567 & SLC6A4 5-HTTLPR/intron 2 VNTR & 121 & 2 & 0.191 & 0.054 \\
\hline SLC6A4 5-HTTLPR & HTR5A rs6320 & 141 & 2 & 0.069 & 0.057 \\
\hline HTR1A rs6295 & SLC6A4 5-HTTLPR/intron 2 VNTR & 122 & 2 & 0.197 & 0.064 \\
\hline HTR1A rs6295 & ITGB3 rs5918 & 138 & 2 & 0.026 & 0.070 \\
\hline HTR $2 A$ rs6311/rs6313 & SLC6A4 5-HTTLPR & 140 & 2 & 0.077 & 0.071 \\
\hline SLC6A4 5-HTTLPR & ITGB3 rs5918 & 140 & 2 & 0.060 & 0.071 \\
\hline$H T R 2 A$ rs6311/rs6313 & HTR5A rs1800883/rs6320 & 120 & 2 & 0.128 & 0.077 \\
\hline HTR1A rs6295 & ITGB3 rs15908 & 135 & 2 & 0.072 & 0.078 \\
\hline$H T R 5 A$ rs1800883 & SLC6A4 5-HTTLPR/intron 2 VNTR & 120 & 2 & 0.151 & 0.078 \\
\hline HTR1A rs6295 & ITGB3 rs5918/rs15908 & 127 & 2 & 0.114 & 0.085 \\
\hline SLC6A4 5-HTTLPR & HTR5A rs1800883/rs6320 & 123 & 2 & 0.124 & 0.104 \\
\hline SLC6A4 5-HTTLPR & ITGB3 rs15908 & 135 & 2 & 0.066 & 0.110 \\
\hline SLC6A4 5-HTTLPR/intron 2 VNTR & HTR1A rs6295/rs878567 & 90 & 2 & 0.223 & 0.120 \\
\hline SLC6A4 5-HTTLPR/intron 2 VNTR & ITGB3 rs5918/rs15908 & 97 & 2 & 0.216 & 0.125 \\
\hline SLC6A4 5-HTTLPR & HTR1A rs6295 & 139 & 2 & 0.060 & 0.130 \\
\hline$H T R 5 A$ rs6320 & SLC6A4 5-HTTLPR/intron 2 VNTR & 123 & 2 & 0.127 & 0.130 \\
\hline SLC6A4 5-HTTLPR/intron 2 VNTR & HTR5A rs1800883/rs6320 & 86 & 2 & 0.180 & 0.130 \\
\hline SLC6A4 5-HTTLPR & $H T R 1 A$ rs 878567 & 139 & 2 & 0.060 & 0.150 \\
\hline HTR5A rs1800883 & ITGB3 rs5918/rs15908 & 129 & 2 & 0.078 & 0.150 \\
\hline$I T G B 3$ rs 15908 & $H T R 5 A$ rs1800883 & 139 & 2 & 0.054 & 0.160 \\
\hline$H T R 2 A$ rs6311/rs6313 & SLC6A4 5-HTTLPR/intron 2 VNTR & 125 & 2 & 0.176 & 0.160 \\
\hline$H T R 1 A$ rs 878567 & ITGB3 rs15908 & 136 & 2 & 0.062 & 0.170 \\
\hline ITGB3 rs5918/rs15908 & HTR5A rs1800883/rs6320 & 101 & 2 & 0.077 & 0.340 \\
\hline
\end{tabular}

Only results with $R^{2}$ above 0 and $P$ value lower than 1.0 are shown

tion of a specific marker and one significantly undertransmitted haplotype. This gene maps to a linkage region previously identified for autism, which has been suggested to contain a locus associated with restrictiverepetitive behaviors (Alarcón et al. 2002; Auranen et al. 2002). The 5-HT5A receptor is mainly expressed in the CNS (Rees et al. 1994) but not much is known regarding its specific function. HTR5A knockout mice show increased locomotor and exploratory behavior in novel environments but no change in anxiety-related behaviors (Grailhe et al. 1999). Activation of this receptor in phase-shift studies also suggests a role in circadian rhythm (Sprouse et al. 2004), which is impaired in autistic patients with sleep problems (Richdale and Prior 1995). While intriguing, this result should be interpreted with caution. We did not correct for multiple testing, as for small sample sizes common procedures such as the Bonferroni correction, while reducing the frequency of Type I errors, greatly increase the probability of Type II errors, considerably increasing the likelihood of missing out on genes of small effect (Feise 2002). We therefore favor replication in a larger independent dataset to properly assess the relevance of this finding.

We further identified a significant two-way interaction between markers in SLC6A4 and ITGB3, indicating that epistasis between variants in these two genes is associated with increased risk to autism, even though the same markers do not show an individual association with the disease. This result may illustrate an extreme case that could, however, be common for complex traits, in which testing for interaction between genes uncovers a genetic liability dependent on gene interaction even when the genes involved show no independent main effect on the phenotype. The most significant model associated with autism was a three- 
way combination between $S L C 6 A 4$, ITGB3, and $H T R 5 A$, with an increased testing balanced accuracy and correctly classifying $67 \%$ of the individuals tested. Interpretation of this model using an interaction dendogram shows a strong synergistic effect between $S L C 6 A 4$ and ITGB3 markers, but an additive effect of $H T R 5 A$, consistent with the independent main effect found for HTR5A in association with autism.

Significant independent effects in the regulation of 5-HT levels were observed for markers at SLC6A4 and $I T G B 3$, as expected given our previous observation of an association of SLC6A4 variants with serotonin distribution in this sample, and reports of these two genes as QTLs on chromosome $17 \mathrm{q}$ for whole blood serotonin (Weiss et al. 2004, 2005a, 2005b). Importantly, an overlapping linkage peak on $17 \mathrm{q}$ has been reported for autism (Stone et al. 2004; Cantor et al. 2005; Sutcliffe et al. 2005), pointing to the SLC6A4 and ITGB3 genes as prime candidates for autism etiology. Previous studies have reported the association of various polymorphisms in SLC6A4 with autism, which we do not replicate in our population. A possible explanation is that our sample size is inadequate for detection of this effect, and/or that the tested loci are not causative but in somewhat weak linkage disequilibrium (LD) with the true causative mutation. However, as discussed in Coutinho et al. (2004), we favor an explanation for this discrepancy residing on the frequency of hyperserotonemia in different samples. Only $11.4 \%$ of our patients have hyperserotonemia. We therefore propose that while genetic variants associated with platelet hyperserotonemia are also contributing to autism susceptibility, these are not as frequent in our population. In this context, it would be interesting to find out whether hyperserotonemia is more frequent in samples in which the SLC6A4 gene has been found associated with autism. The present study provides further evidence for a common genetic architecture underlying autism and regulation of serotonin levels by showing that the epistatic interaction of genetic variants of these two genes contributes to the determination of 5-HT levels and is associated with autism. Two very recent studies, in which association of ITGB3 with autism and whole blood serotonin levels was reported (Weiss et al. 2006a) and it was suggested that ITGB3 may interact with SLC6A4 in mediating autism susceptibility (Weiss et al. 2006b) lend further support to our hypothesis. Notably, these were the single nonadditive gene interactions consistent for autism and serotonin distribution. Interpretation of the joint results for the autism and 5-HT phenotypes indicates that the HTR5A gene, independently or in combination with $S L C 6 A 4$ and $I T G B 3$, is not a major factor in the regulation of serotonin levels and thus likely does not contribute to autism etiology through the same mechanism at the biological level. Other gene-gene interactions were significant for the determination of platelet serotonin distribution in our sample. For instance, the results suggest that the increased 5-HT reuptake associated with specific functional variants of the SLC6A4 gene (Meltzer and Arora 1988; Lesch et al. 1996; Greenberg et al. 1999) could be reinforced by increases in the synthesis of 5-HT mediated by sequence alterations in the TPH1 promoter (Sun et al. 2005). Evidence of a contribution to 5-HT level distribution was found for interactions involving $S L C 6 A 4$ and HTR1D or HTR5A, and also ITGB3 and HTR1A or HTR5A. An involvement of these molecules was expected, given the roles of the encoded molecules in serotonin transmission or metabolism, but we found no evidence for a meaningful impact on the autistic phenotype.

The significant main effect and significant genetic interactions between candidate genes here reported cannot explain the entirety of trait variation. This is not surprising, as the serotonin system pathway includes a large number of components, and genetic interactions not detected in our sample, as well as gene-environment effects that were not accounted in the analysis, are likely contributors to these complex phenotypes. The power of our analysis to detect genetic effects with a minor contribution, however, was limited by the small sample size and thus replication in a larger independent sample is important.

By showing a common genetic architecture underlying the two traits, the results strongly suggest that, at least for a proportion of autistic subjects, a genetically determined increase in serotonin levels, with likely important consequences for brain development and function, contributes to autism etiology. We find independent and interaction effects of the SLC6A4 and $I T G B 3$ genes to contribute to the full range of serotonin concentrations. Since only about $11.4 \%$ of our patients have hyperserotonemia, the majority of individuals tested fall in the normal portion of the 5-HT distribution, indicating that they have genotypes at either gene and/or gene combinations that will determine normal platelet serotonin levels. Only the minority of hyperserotonemic patients are likely to have the fatal combination of variants in the SLC6A4 and $I T G B 3$ genes that will significantly contribute to a dysfunction in serotonin regulation, which is reflected in the increased platelet serotonin levels and may lead to autism. We suggest that while each gene independently strongly contributes to the 5-HT trait variation in the normal range, the interaction of specific delete- 
rious variants of both genes will potentiate serotonin dysregulation, reflected in increased serotonin levels in the periphery and leading to brain dysfunction/disease. We cannot rule out that each gene does not independently contribute to autism in individuals with hyperserotonemia, but do find that the interaction has a stronger effect on the phenotype that can be detected even in a small sample of individuals in which hyperserotonemia is observed.

The biological mechanism, however, has yet to be determined. A role for the serotonin transporter is biologically sound, as this molecule is chiefly responsible for the removal of serotonin from the synapses. However, the association of specific transporter gene variants with autism has not been consistent among studies, even though it is clearly associated with serotonin level variation. Janusonis (2005) has established a theoretical model for serotonin release from gut enterochromaffin (EC) cells to the blood stream proposing that 5-HT levels are strongly dependent on a serotonin monitoring factor in the extracellular space that adjusts 5-HT release accordingly, while taking into account the impact of mechanisms for 5-HT clearance, namely the reuptake by the serotonin transporter and the degradation by metabolic enzymes. The model proposes that autistic individuals will have a molecular defect that impairs the feedback mechanism regulating serotonin release according to 5-HT levels, with the transporter and other molecules involved in serotonin clearance acting as modifiers. The evidence gathered in the present study indicates that the $\beta 3$ integrin subunit may be involved in the regulation of serotonin release. It is known that $\alpha \operatorname{IIb} \beta 3$ integrin plays a key role in the regulation of platelet aggregation and serotonin secretion, through an outside-in signaling mechanism that is regulated by the Leu33Pro ITGB3 polymorphism (Sajid et al. 2002; Vijayan et al. 2005). While the existence of the $\beta 3$ integrin subunit in the EC cells model has not been documented, and thus no simple projection/extrapolation can be made, the role of $I T G B 3$ in platelets and its expression in the brain, where $\beta 3$ integrins mediate functional pre and postsynaptic maturation of synapses, as well as evidence that blocking integrin activity after spinal cord injury improves serotonergic innervation (Oatway et al. 2005), support this hypothesis.

In summary, we present evidence for a common genetic mechanism underlying autism and serotonin level distribution, thus providing a molecular explanation for the association of platelet hyperserotonemia with autism and suggesting a plausible pathological mechanism. It is worth remarking that the alterations in platelet 5-HT levels do not necessarily imply changes in brain serotonin levels, but do reflect the dysfunction of brain expressed genes with consequences in brain development and function that may lead to autism symptomatology. Functional studies are now required to assess the biological meaning of the statistical interactions identified in this work, but the findings are compatible with biological observations and theoretical models, and thus provide a solid basis for functional work. Autism is a highly complex disorder, and testing for gene epistasis in association with specific disease associated phenotypes is shown to be a powerful strategy towards the identification of autism pathophysiology.

Acknowledgments We thank the autistic patients, their relatives and the healthy blood donors for their collaboration in this study. This work was supported by a Portuguese grant from the Fundação para a Ciência e a Tecnologia (FCT) (POCTI/39636/ ESP/2001). Ana M. Coutinho was supported by a grant from FCT (SFRH/BD/3145/2000) and from the Fundo Social Europeu (III Quadro Comunitário de Apoio).

\section{References}

Abecasis GR, Cardon LR, Cookson WO (2000) A general test of association for quantitative traits in nuclear families. Am J Hum Genet 66:279-292

Abney M, McPeek MS, Ober C (2001) Broad and narrow heritabilities of quantitative traits in a founder population. Am J Hum Genet 68:1302-1307

Alarcón M, Cantor RM, Liu J, Gilliam TC, Geschwind DH (2002) Evidence for a language quantitative trait locus on chromosome $7 \mathrm{q}$ in multiplex autism families. Am J Hum Genet 70:60-71

American Psychiatric Association (1994) Diagnostic and statistical manual of mental disorders-fourth edition (DSM-IV). American Psychiatric Association, Washington DC

Auranen M, Vanhala R, Varilo T, Ayers K, Kempas E, Ylisaukko-Oja T, Sinsheimer JS, Peltonen L, Jarvela I (2002) A genomewide screen for autism-spectrum disorders: evidence for a major susceptibility locus on chromosome 3q25-27. Am J Hum Genet 71:777-790

Barrett S, Beck JC, Bernier R, Bisson E, Braun TA, Casavant TL, Childress D, Folstein SE, Garcia M, Gardiner MB, Gilman S, Haines JL, Hopkins K, Landa R, Meyer NH, Mullane JA, Nishimura DY, Palmer P, Piven J, Purdy J, Santangelo SL, Searby C, Sheffield V, Singleton J, Slager S et al (1999) An autosomal genomic screen for autism. Collaborative linkage study of autism. Am J Med Genet 88:609-615

Bradford Y, Haines J, Hutcheson H, Gardiner M, Braun T, Sheffield V, Cassavant T, Huang W, Wang K, Vieland V, Folstein S, Santangelo S, Piven J (2001) Incorporating language phenotypes strengthens evidence of linkage to autism. Am J Med Genet 105:539-547

Cantor RM, Kono N, Duvall JA, Alvarez-Retuerto A, Stone JL, Alarcón M, Nelson SF, Geschwind DH (2005) Replication of autism linkage: fine-mapping peak at 17q21. Am J Hum Genet 76:1050-1056 
Clayton D (1999) A generalization of the transmission/disequilibrium test for uncertain-haplotype transmission. Am J Hum Genet 65:1170-1177

Coffey CS, Hebert PR, Ritchie MD, Krumholz HM, Gaziano JM, Ridker PM, Brown NJ, Vaughan DE, Moore JH (2004) An application of conditional logistic regression and multifactor dimensionality reduction for detecting gene-gene interactions on risk of myocardial infarction: the importance of model validation. BMC Bioinformatics 5:49

Cook EH Jr, Arora RC, Anderson GM, Berry-Kravis EM, Yan SY, Yeoh HC, Sklena PJ, Charak DA, Leventhal BL (1993) Platelet serotonin studies in hyperserotonemic relatives of children with autistic disorder. Life Sci 52:2005-2015

Coutinho AM, Oliveira G, Morgadinho T, Fesel C, Macedo TR, Bento C, Marques C, Ataíde A, Miguel T, Borges L, Vicente AM (2004) Variants of the serotonin transporter gene (SLC6A4) significantly contribute to hyperserotonemia in autism. Mol Psychiatry 9:264-271

Culverhouse R, Klein T, Shannon W (2004) Detecting epistatic interactions contributing to quantitative traits. Genet Epidemiol 27:141-152

Devlin B, Cook EH Jr, Coon H, Dawson G, Grigorenko EL, McMahon W, Minshew N, Pauls D, Smith M, Spence MA, Rodier PM, Stodgell C, Schellenberg GD (2005) Autism and the serotonin transporter: the long and short of it. Mol Psychiatry 10:1110-1116

Feise RJ (2002) Do multiple outcome measures require p-value adjustment? BMC Med Res Methodol 2:8

Good P (2000) Permutation tests. Springer, Berlin, Heidelberg New York

Grailhe R, Waeber C, Dulawa SC, Hornung JP, Zhuang X, Brunner D, Geyer MA, Hen R (1999) Increased exploratory activity and altered response to LSD in mice lacking the 5HT(5A) receptor. Neuron 22:581-591

Greenberg BD, Tolliver TJ, Huang SJ, Li Q, Bengel D, Murphy DL (1999) Genetic variation in the serotonin transporter promoter region affects serotonin uptake in human blood platelets. Am J Med Genet 88:83-87

Griffiths R (1984) The abilities of young children. University of London Press, London

Hastie T, Tibshirani R, Friedman J (2001) The elements of statistical learning. Springer, Berlin Heidelberg New York

Janusonis S (2005) Statistical distribution of blood serotonin as a predictor of early autistic brain abnormalities. Theor Biol Med Model 2:27

Lahiri DK, Nurnberger JI Jr (1991) A rapid non-enzymatic method for the preparation of HMW DNA from blood for RFLP studies. Nucleic Acids Res 19:5444

Lesch KP, Bengel D, Heils A, Sabol SZ, Greenberg BD, Petri S, Benjamin J, Muller CR, Hamer DH, Murphy DL (1996) Association of anxiety-related traits with a polymorphism in the serotonin transporter gene regulatory region. Science 274:1527-1531

Lord C, Rutter M, Le Couteur A (1994) Autism diagnostic interview-revised: a revised version of a diagnostic interview for caregivers of individuals with possible pervasive developmental disorders. J Autism Dev Disord 24:659-685

Lord C, Cook EH, Leventhal BL, Amaral DG (2000) Autism spectrum disorders. Neuron 28:355-363

McBride PA, Anderson GM, Hertzig ME, Sweeney JA, Kream J, Cohen DJ, Mann JJ (1989) Serotonergic responsivity in male young adults with autistic disorder. Results of a pilot study. Arch Gen Psychiatry 46:213-221

Meltzer HY, Arora RC (1988) Genetic control of serotonin uptake in blood platelets: a twin study. Psychiatry Res 24:263-269
Moore JH (2003a)In: Raidl $G$ et al (eds) Lecture notes in computer science, vol 2611. Springer, Berlin Heidelberg New York, pp 99-106

Moore JH (2003b) The ubiquitous nature of epistasis in determining susceptibility to common human diseases. Hum Hered 56:73-82

Moore JH (2004) Computational analysis of gene-gene interactions using multifactor dimensionality reduction. Expert Rev Mol Diagn 4:795-803

Moore JH (2005) A global view of epistasis. Nat Genet 37:13-14

Moore JH, Gilbert JC, Tsai CT, Chiang FT, Holden T, Barney N, White BC (2006) A flexible computational framework for detecting, characterizing, and interpreting statistical patterns of epistasis in genetic studies of human disease susceptibility. J Theor Biol 241:252-261

Oatway MA, Chen Y, Bruce JC, Dekaban GA, Weaver LC (2005) Anti-CD11d integrin antibody treatment restores normal serotonergic projections to the dorsal, intermediate, and ventral horns of the injured spinal cord. J Neurosci 25:637-647

Ober C, Abney M, McPeek MS (2001) The genetic dissection of complex traits in a founder population. Am J Hum Genet 69:1068-1079

Rees S, den Daas I, Foord S, Goodson S, Bull D, Kilpatrick G, Lee M (1994) Cloning and characterisation of the human 5HT5A serotonin receptor. FEBS Lett 355:242-246

Richdale AL, Prior MR (1995) The sleep/wake rhythm in children with autism. Eur Child Adolesc Psychiatry 4:175186

Ritchie MD, Hahn LW, Roodi N, Bailey LR, Dupont WD, Parl FF, Moore JH (2001) Multifactor-dimensionality reduction reveals high-order interactions among estrogen-metabolism genes in sporadic breast cancer. Am J Hum Genet 69:138-147

Sajid M, Vijayan KV, Souza S, Bray PF (2002) PlA polymorphism of integrin beta 3 differentially modulates cellular migration on extracellular matrix proteins. Arterioscler Thromb Vasc Biol 22:1984-1989

Schopler E, Reichler RJ, Renner BR (1988) The childhood autism rating scale (CARS). Western Psychological Services, Los Angeles

Sham PC, Curtis D (1995) An extended transmission/disequilibrium test (TDT) for multi-allele marker loci. Ann Hum Genet 59:323-336

Sprouse J, Reynolds L, Braselton J, Schmidt A (2004) Serotonininduced phase advances of SCN neuronal firing in vitro: a possible role for 5-HT5A receptors? Synapse 54:111-118

Stephens M, Smith NJ, Donnelly P (2001) A new statistical method for haplotype reconstruction from population data. Am J Hum Genet 68:978-989

Stone JL, Merriman B, Cantor RM, Yonan AL, Gilliam TC, Geschwind DH, Nelson SF (2004) Evidence for sex-specific risk alleles in autism spectrum disorder. Am J Hum Genet 75:1117-1123

Sun HS, Fann CS, Lane HY, Chang YT, Chang CJ, Liu YL, Cheng AT (2005) A functional polymorphism in the promoter region of the tryptophan hydroxylase gene is associated with alcohol dependence in one aboriginal group in Taiwan. Alcohol Clin Exp Res 29:1-7

Sutcliffe JS, Delahanty RJ, Prasad HC, McCauley JL, Han Q, Jiang L, Li C, Folstein SE, Blakely RD (2005) Allelic heterogeneity at the serotonin transporter locus (SLC6A4) confers susceptibility to autism and rigid-compulsive behaviors. Am J Hum Genet 77:265-279

Thornton-Wells TA, Moore JH, Haines JL (2004) Genetics, statistics and human disease: analytical retooling for complexity. Trends Genet 20:640-647 
Velez DR, White BC, Motsinger AA, Bush WS, Ritchie MD, Williams SM, Moore JH (2006) A balanced accuracy metric for epistasis modeling in imbalanced datasets using multifactor dimensionality reduction. Genet Epidemiol (in press)

Vijayan KV, Liu Y, Sun W, Ito M, Bray PF (2005) The Pro33 isoform of integrin beta3 enhances outside-in signaling in human platelets by regulating the activation of serine/ threonine phosphatases. J Biol Chem 280:21756-21762

Weiss LA, Veenstra-Vanderweele J, Newman DL, Kim SJ, Dytch H, McPeek MS, Cheng S, Ober C, Cook EH Jr, Abney M (2004) Genome-wide association study identifies ITGB3 as a QTL for whole blood serotonin. Eur J Hum Genet 12:949-954

Weiss LA, Abney M, Cook EH Jr, Ober C (2005a) Sex-specific genetic architecture of whole blood serotonin levels. Am J Hum Genet 76:33-41

Weiss LA, Abney M, Parry R, Scanu AM, Cook EH Jr, Ober C (2005b) Variation in ITGB3 has sex-specific associations with plasma lipoprotein(a) and whole blood serotonin levels in a population-based sample. Hum Genet 117:81-87

Weiss LA, Kosova G, Delahanty RJ, Jiang L, Cook EH Jr, Ober C, Sutcliffe JS (2006a) Variation in ITGB3 is associated with whole-blood serotonin level and autism susceptibility. Eur J Hum Genet 14:923-931

Weiss LA, Ober C, Cook EH Jr (2006b) ITGB3 shows genetic and expression interaction with SLC6A4. Hum Genet 120:93-100

Whitaker-Azmitia PM (2005) Behavioral and cellular consequences of increasing serotonergic activity during brain development: a role in autism? Int J Dev Neurosci 23:75-83

Zill P, Buttner A, Eisenmenger W, Moller HJ, Ackenheil M, Bondy B (2005) Analysis of tryptophan hydroxylase I and II mRNA expression in the human brain: A post-mortem study. J Psychiatr Res doi:10.1016/j.jpsychires.2005.05.004 